\title{
Electrochemical and optical biosensors for biological sensing applications
}

\author{
Kanokwan Charoenkitamorn $^{\mathrm{a}}$, Abdulhadee Yakoh $^{\mathrm{b}}$, Sakda Jampasa ${ }^{\mathrm{b}}$, Sudkate Chaiyo ${ }^{\mathrm{b}, \mathrm{c}}$, \\ Orawon Chailapakul ${ }^{\mathrm{c}, *}$ \\ ${ }^{a}$ Department of Chemistry, Faculty of Science, Silpakorn University, Nakorn Pathom 73000 Thailand \\ b Institute of Biotechnology and Genetic Engineering, Chulalongkorn University, Bangkok 10330 Thailand \\ c Electrochemistry and Optical Spectroscopy Center of Excellence (EOSCE), Department of Chemistry, \\ Faculty of Science, Chulalongkorn University, Bangkok 10330 Thailand
}

*Corresponding author, e-mail: chaorawon@yahoo.com, corawon@chula.ac.th

Received 13 Jun 2020

Accepted 22 Jun 2020

\begin{abstract}
Biosensors are analytical tools that play an important role in advanced applications, especially in the monitoring of biological molecules related to health conditions. A variety of biosensors have been described in this review to emphasize the important applications in the biological field. These biosensors are categorized into four groups depending on the bioreceptor molecules, including enzymatic biosensors, immuno-based biosensors, DNA-based biosensors, and other interesting biosensors. Many platforms and materials have been developed with various benefits. The detection principles of the biosensors in this review are focused on optical and electrochemical techniques due to their characteristic advantages. Information of using novel materials for fabrication of biosensors is also provided.
\end{abstract}

KEYWORDS: Biosensors, enzymatic biosensors, immuno-based biosensors, DNA-based biosensors, electrochemical detection, optical detection

\section{INTRODUCTION}

Biosensors are analytical tools for converting biological responses to detectable signals. The recognition system of a biosensor utilizes a biochemical mechanism that is highly specific and independent of physical limitations such as $\mathrm{pH}$ and temperature $[1,2]$. Research and development of biosensors have been universally studied, contributing to advancements in drug discovery, monitoring disease-causing bacteria and markers, and detecting pollutants. The characteristics of biosensors are (i) selectivity to the analytes of interest, (ii) reproducibility to produce identical responses, (iii) stability under ambient disturbances, (iv) sensitivity to analytes down to nano to femto-levels to ensure their existence in the sample, and (v) linearity in the range of analyte concentrations, which is related to the accuracy of the measured response [3].

The typical components of a biosensor are shown in Fig. 1, including the analyte of interest, bioreceptor molecules, transducer, electronic system, and display [2]. In a biosensor, the most important component is the bioreceptor, which is designed to specifically interact with the analyte of interest. The key requirement of bioreceptors is high selectivity to the analyte in the matrix of the sample and contaminant. Biosensors are categorized into four groups based on their bioreceptors, including enzymes, antibodies/antigens, nucleic acids, and others [1]. Various biosensor platforms for the application of biological compound detection have been employed on a variety of transducers, such as optical, electrical, electrochemical, and thermal transducers. Optical spectroscopy and electrochemistry are the most preferred transducers used in biosensors due to their characteristic strength [4]. Optical biosensors, including fluorescence and colorimetry, work on the principle of the generation of an optical signal from the specific on-site interaction of biosensor elements such as enzyme substrates and metal nanoparticles [5]. In electrochemical biosensors, electrochemical signals are produced by the redox reaction of electroactive species in the biosensor system [6]. In this review, we emphasize an overview of optical and electrochemical biosensors for the application of biological compound detection categorized by their bioreceptor mechanisms.

\section{Enzymatic biosensors}

An "enzyme biosensor" is an analytical device integrating an enzyme as a bioreceptor with a trans- 


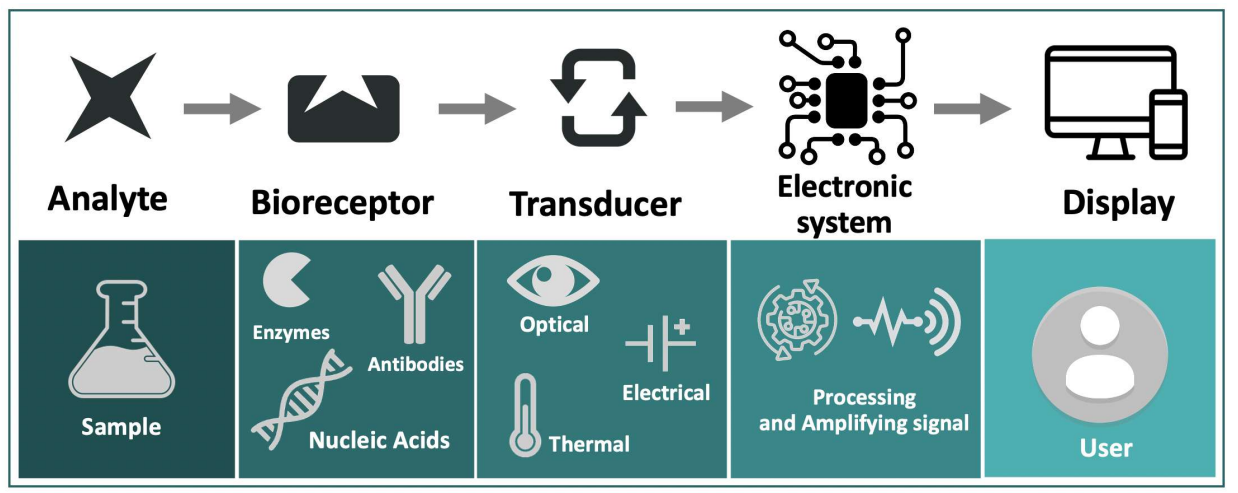

Fig. 1 Typical components of a biosensor.

Table 1 Summarized data of the enzymatic biosensors based on electrochemical and optical detection.

\begin{tabular}{|c|c|c|c|c|c|c|}
\hline Detection & Technique & Analyte(s) & Enzyme & LOD & Linear range & Year \\
\hline \multirow{12}{*}{$\begin{array}{l}\text { Electro- } \\
\text { chemical }\end{array}$} & Amperometry & Lactate & Lactate oxidase & $19 \mu \mathrm{M}$ & $50 \mu \mathrm{M}-10 \mathrm{mM}$ & 2019 [7] \\
\hline & Amperometry & Lactate & Lactate oxidase & $5.0 \mu \mathrm{M}$ & $5 \mu \mathrm{M}-5.0 \mathrm{mM}$ & $2019[8]$ \\
\hline & Amperometry & Cholesterol & Cholesterol oxidase & $0.52 \mathrm{mM}$ & $0.6-6.0 \mathrm{mM}$ & 2016 [9] \\
\hline & Amperometry & Cholesterol & Cholesterol oxidase & $0.99 \mathrm{mg} / \mathrm{dl}$ & $3.9-773.4 \mathrm{mg} / \mathrm{dl}$ & 2015 [10] \\
\hline & Amperometry & Cholesterol & Cholesterol oxidase & $0.25 \mathrm{mg} / \mathrm{dl}$ & $0.4-270.7 \mathrm{mg} / \mathrm{dl}$ & $2015[11]$ \\
\hline & Amperometry & Glucose & Glucose oxidase & $0.29 \mathrm{mM}$ & $1-10 \mathrm{mM}$ & 2015 [12] \\
\hline & Amperometry & Cholesterol & Cholesterol oxidase & $1 \mu \mathrm{M}$ & $50 \mu \mathrm{M}-10 \mathrm{mM}$ & $2014[13]$ \\
\hline & Amperometry & Glucose & Glucose oxidase & - & $0-10 \mathrm{mM}$ & $2011[14]$ \\
\hline & Amperometry & Cholesterol & Cholesterol oxidase & $1 \mathrm{nM}$ & $1 \mu \mathrm{M}-7 \mathrm{mM}$ & $2011[15]$ \\
\hline & Amperometry & Glucose & Glucose oxidase & $0.21 \mathrm{mM}$ & $0-100 \mathrm{mM}$ & 2009 [16] \\
\hline & & Lactate & Lactate oxidase & $0.36 \mathrm{mM}$ & $0-50 \mathrm{mM}$ & \\
\hline & & Uric acid & Uricase & $1.38 \mathrm{mM}$ & $0-35 \mathrm{mM}$ & \\
\hline \multirow[t]{6}{*}{ Optical } & Fluorescence & Organophosphorus and & Acetylcholinesterase & $0.05 \mathrm{mg} / 1$ (pirimicarb) & - & 2017 [17] \\
\hline & spectroscopy & carbamate insecticides & and Choline oxidase & $0.01 \mathrm{mg} / 1$ (dichlorvos) & & \\
\hline & & $\begin{array}{l}\text { (pirimicarb, dichlorvos } \\
\text { and carbaryl) }\end{array}$ & & $0.01 \mathrm{mg} / 1$ (carbaryl) & & \\
\hline & Colorimetry & Glucose & Glucose oxidase & $0.5 \mathrm{mM}$ & - & $2010[18]$ \\
\hline & & Lactate & Lactate oxidase & $1.0 \mathrm{mM}$ & & \\
\hline & & Uric acid & Uricase & $0.1 \mathrm{mM}$ & & \\
\hline
\end{tabular}

ducer (e.g., electrode) to generate a detectable signal correlated with a substrate/inhibitor/co-factor concentration. The glucose sensor is one of the most universal examples of the enzyme-based biosensors that could save millions of lives from diabetes. In essence, there are two main classes of enzymatic assays: enzyme catalysis and enzyme inhibition. For enzyme catalysis, the presence of the analyte can increase the enzyme catalytic activity. Accordingly, the response signal (such as glucose, lactate, uric acid, and cholesterol) is increased. In contrast, for enzyme inhibition, the presence of analyte can inhibit the catalytic activity of the enzyme-substrate since the analyte takes part as an inhibitor in the substrate-enzyme system. Organophosphorus pesticides, for instance, are a group of common inhibitors that can inhibit the catalytic activity of acetylcholinesterase and its substrate. Thus, a decrease in the response signal is observed. Selected examples of enzymatic biosensors published by our group are presented in Table 1.

\section{Immuno-based biosensors}

Immunosensors are biosensors that were established based on the high affinity of antibodies to form a stable complex with their antigens [1]. There is a specific antibody for each antigen; thus, the detection of antigen/antibody of interest can be performed in the presence of others. The application of antigen/antibody formation is important in medical diagnostics for many diseases [19]. Several optical and electrochemical transducers have been employed.

One of the most attractive optical biosensors is the combination of antigen-antibody specific binding and the catalytic reaction of labeling enzymes that enable highly selective and sensitive biochemical assays. Alkaline phosphatase (ALP) is 


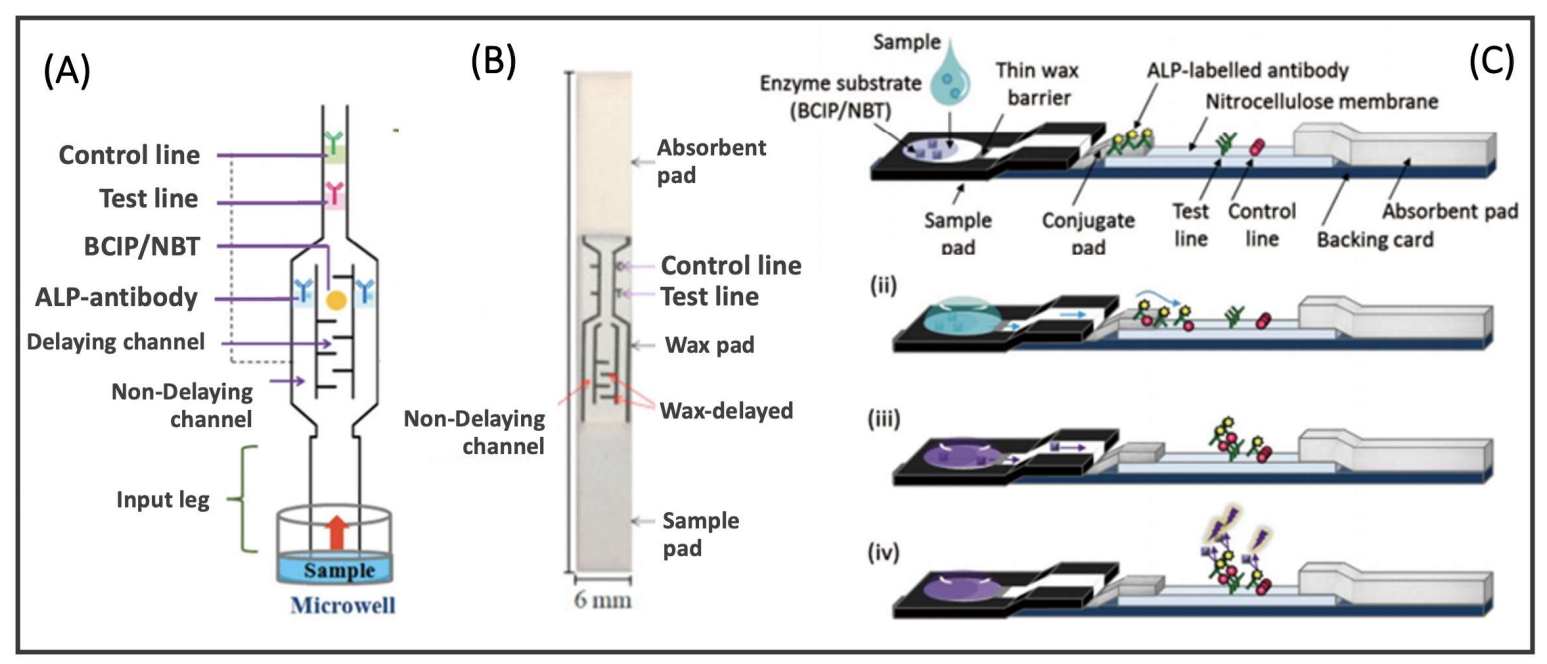

Fig. 2 Illustration of (A) automated paper-based biosensor for hCG detection [20], (B) automated wax-printed paperbased lateral flow device for AFP detection [21] and (C) wax-assisted one-step lateral flow test devices for mouse IgG detection [22].

a frequently used enzyme for immunosystem labeling [20-22]. The introduction of 5-bromo-4chloro-3'-indolyl phosphate $p$-toluidine salt/nitroblue tetrazolium chloride (BCIP/NBT) and ALP substrate into a system containing ALP-labeled antibodies produced an insoluble blue to purple product that can be observed visually [20-22]. In the common scheme of ALP/BCIP/NBT-based immunosensors, the operation requires the addition of an enzyme-substrate after antigen-antibody complex formation, necessitates a complicated multistep process including mixing, washing, and incubation [20]. Therefore, many automated immunosensors have been developed by creating a delay platform and pre-depositing enzyme substrates to allow the sequential reagent delivery system by a single introduction of the sample solution, which has been applied for the detection of various biological molecules such as human chorionic gonadotropin (hCG) [20], alpha-fetoprotein (AFP) [21], and mouse IgG [22]. The designs of automated immunosensors are shown in Fig. 2.

Although the use of the catalytic reaction of a labeling enzyme provides high sensitivity, some of the disadvantages include instability of the enzyme and substrate and the increased complexity of the assay. Moreover, the addition of a substrate solution is required to produce a measurable signal. Metal nanoparticles are popular labeling materials for antigens/antibodies in immunoassays. Compared to an enzyme-labeled immunosensor, the color of particular metal nanoparticles occurs naturally, and there is no need for the substrate solution. Gold nanoparticles (AuNPs) have gained much attention as metal nanoparticles in colorimetric immunosensors because of their long-term stability, easily controllable size distribution, and good compatibility with biological molecules, such as antibodies, antigens, proteins, DNA, and RNA [19,23]. AuNPconjugated antibodies/antigens have been applied in various immunoassay platforms for the detection of Salmonella typhi [23], ractopamine [24] and cortisol [25]. However, the sensitivity of AuNPbased immunosensors was not sufficient in a particular application. Many researchers have proposed procedures to enhance the sensitivity, such as modifying the surface of AuNPs with a europium (III)-chelate fluorophore-doped silica shell for the detection of human thyroid-stimulating hormone (hTSH) [26] and using a silver enhancement solution after antigen-antibody complex formation for the detection of cortisol [27]. This approach demonstrated the versatility of metal nanoparticles in the application of immunosensors.

Electrochemical detection is another popular platform employed in biosensors for ultrasensitive detection. The important key of electrochemical immunosensors is the presence of electroactive species in the system. The electroactive species could exist either as a labeling agent of an antibody/antigen or working solution or the generated electroactive species products. Various electroactive species have been used as labeled agents, such as AuNPs for the detection of hCG [28], Salmonella typhi [29] and 


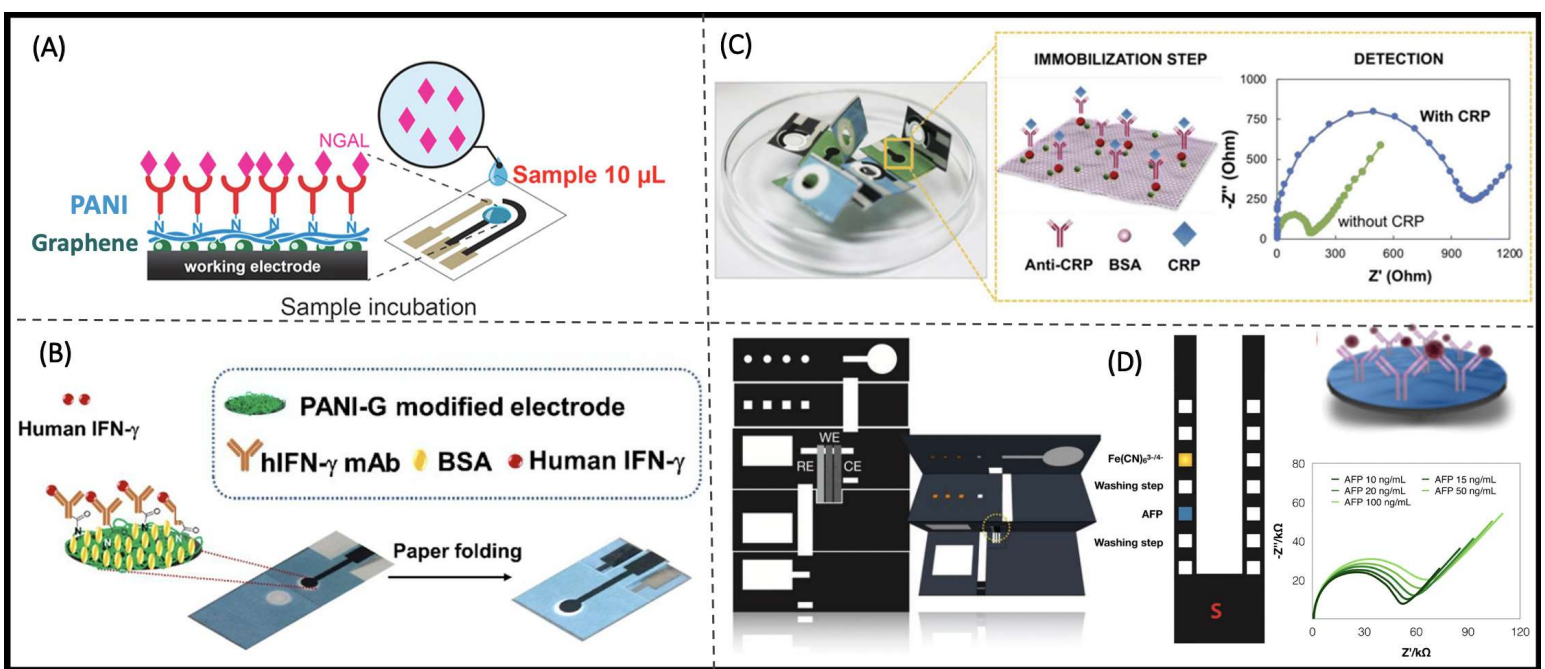

Fig. 3 Illustration of (A) G/PANI-modified screen-printed carbon electrode for NGAL detection [35], (B) PANImodified screen-printed graphene electrode for IFN- $\gamma$ detection [36], (C) origami paper-based immunosensor for CRP detection [37] and (D) stopped-flow 3D sequential microfluidic platform for label-free electrochemical immunosensor of AFP [38].

leptospirosis [30], platinum nanoparticles (PtNPs) for the detection of hCG [31], anthraquinone for the detection of c-reactive protein (CRP) [32] and Cd$\mathrm{Se} / \mathrm{ZnS}$ quantum dots for the detection of phosphorylated bovine serum albumin [33]. Using these labeled materials, the electrochemical signals directly generated their unique electrochemical properties. Moreover, the catalytic enzyme reaction was applied in an electrochemical immunosensor via the reaction of enzyme-labeled antibodies and a particular substrate to generate electroactive species products such as the detection of mouse IgG using ALP as the labeled enzyme and 2-phospho-L-ascorbic acid as the substrate [34].

Label-free immunosensors are platforms that eliminate complicated and time-consuming labeling preparation. The direct conjugation of the target molecule is achieved by capture of antibodies at the electrode surface. In one of these designs, the electrochemical signal was monitored by measuring the changes in the charge transfer efficiency between the electrode and the redox couple $\left[\mathrm{Fe}(\mathrm{CN})_{6}\right]^{3-/ 4-}$ using an electrochemical technique. Modifications of the electrode surface with various nanomaterials were performed to anchor antibodies on the electrochemical transducer surface and enhance the sensitivity of the detection, as shown in Fig. 3. The fabrication of the biorecognition surface was performed via EDC/NHS chemistry. Polyaniline (PANI) and graphene $(\mathrm{G})$ were presented as modifiers on electrodes and applied in a different design for the detection of neutrophil gelatinaseassociated lipocalin (NGAL) (Fig. 3A) [35] and human interferon-gamma (IFN- $\gamma$ ) (Fig. 3B) [36]. Excellent sensitivities were observed due to the electrocatalytic properties and high surface area of the PANI/G nanocomposite. AuNPs were also presented as a modifier for the immobilization of antibodies. The electrodeposition of AuNPs was performed followed by the immobilization of antibodies via Lcysteine and EDC/NHS. This approach was applied in an origami paper-based immunosensor for the detection of CRP, as shown in Fig. 3C [37]. In addition, a stopped-flow 3D sequential microfluidic platform has been developed and applied in label-free electrochemical immunosensors (Fig. 3D) [38]. Using this device, the detection of AFP could be achieved using one-step manipulation, which eliminates the complex procedure of multiple-step reagent manipulation.

\section{DNA-based biosensors}

Biosensors play a vital role in several areas of life science, especially in medical diagnosis. Currently, biosensors are extensively used as tools to accurately identify a disease. However, to access a related biomarker of a disease at an early stage or a superficial level, a sensitive biosensor is required. A biosensor consists of three main parts: a biorecognition element, transducer, and a procedure for displaying data. Among these compo- 


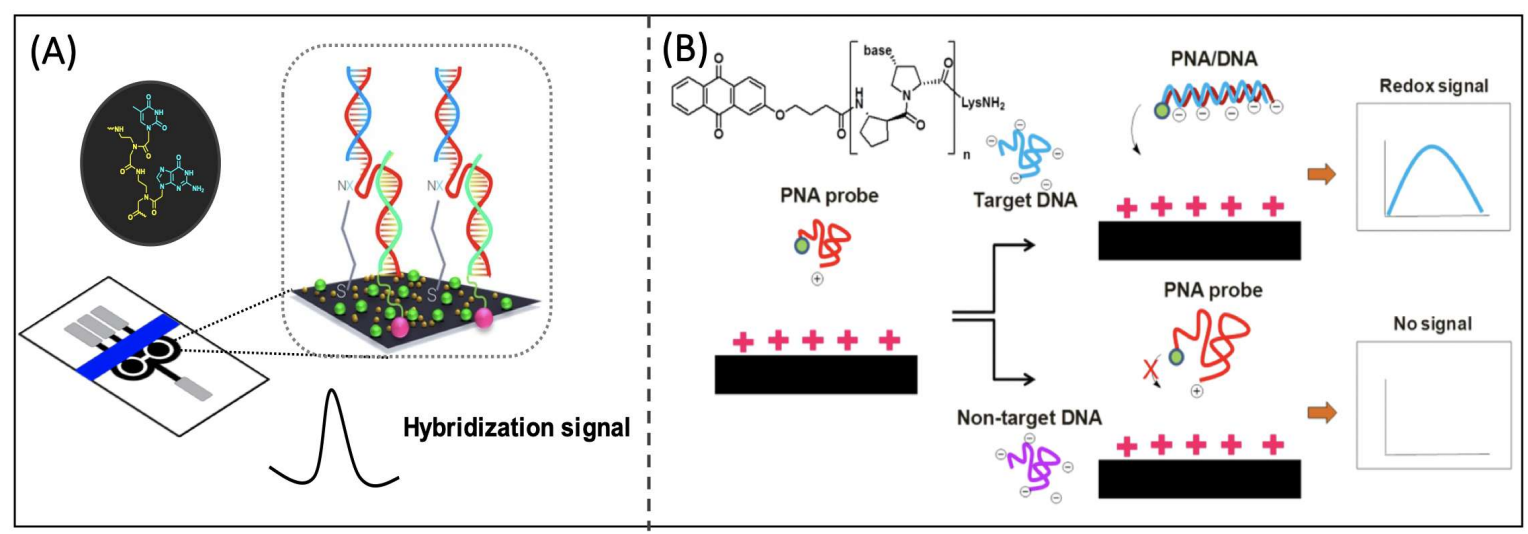

Fig. 4 Illustration of the hybridization-induced conformation (A and B) for the detection of target DNAs [40, 43].

nents, the recognition layers (e.g., enzyme, antibody, DNA, or DNA-analogs and aptamers) are the most significant parts and have been utilized for sensitive and selective binding with the target molecules. According to previous studies, peptide nucleic acid (PNA) probes have been shown to offer higher sensitivity, specificity, and fast hybridization kinetics. Additionally, the hybridization process of PNA requires a shorter probe length than DNA. Recently, a new conformationally restricted pyrrolidinyl PNA was developed. The structure of this newly introduced PNA is made up of a $\alpha / \beta$-peptide backbone derived from $D$-proline/2aminocyclopentanecarboxylic acid (acpcPNA). This structural PNA system exhibits advantages, including a more durable binding affinity and a higher specificity towards a complementary target DNA than the initially discovered PNA or other DNA analogs. Because of these excellent properties, acpcPNA has been widely applied as a sensor probe to detect target biomarkers in combination with various detection methods, such as electrochemical detection and colorimetric detection. Hence, the utilization of acpcPNA probes combined with these strategies for disease identification will be the focus. Electrochemical detection is a promising method for the sensitive and selective determination of target DNAs. The detection principles of this approach are based on the hybridization-induced conformational or resistant changes in redox tags or mediators used (e.g., anthraquinone (AQ) or $\left[\mathrm{Fe}(\mathrm{CN})_{6}\right]^{3-/ 4-}$, resulting in differences in signal responses. For medical diagnosis, acpcPNA has been successfully used as a probe to selectively detect the high-risk group of human papillomavirus DNAs (HPV DNA) and Mycobacterium tuberculosis DNA in practical samples for the evaluation of cervical cancer and tuberculosis, respectively (Fig. 4A) [39-42]. In addition, acpcPNA has been utilized as a specific probe for the detection of isothermally amplified shrimp white spot syndrome virus DNA in agricultural applications (Fig. 4B) [43]. These fabricated platforms might be an alternative tool for broader applications in medical diagnosis.

To the best of our knowledge, colorimetric detection is particularly attractive and can achieve the rapid detection of a disease, as naked-eye observation can only interpret a screening result. To date, colorimetric assays based on the aggregation of nanoparticles, such as silver (AgNPs) and gold nanoparticles (AuNPs) enhancing the signal, have received considerable interest in medical diagnosis. In 2017, Teengam reported a colorimetric assay for the simultaneous detection of virus MERS-CoV, MTB, and HPV DNAs based on acpcPNA-induced nanoparticle aggregation [44]. This proposed platform was successfully applied to determine real DNA samples and provided satisfactory results. By using this method, three DNA sequences related to the target diseases can simultaneously be evaluated, reducing turn-around-time (TAT).

\section{Other applications}

There are biosensors that have not been used in the aforementioned bioreceptors. Numerous chemical substances related to health conditions have been demonstrated. The direct colorimetric assay presented the simplest detection of biological molecules. As the simplest demonstration, the determination of the albumin (AL) to creatinine (CR) ratio has been employed for the screening of diabetes. Bromocresol green was used to evaluate 
Table 2 The merits of other applications of biosensors.

\begin{tabular}{|c|c|c|c|c|}
\hline Receptor & Analyte(s) & Transducer & Description & Ref. \\
\hline- & $\begin{array}{l}\text { Albumin (AL) and } \\
\text { Creatinine (CR) }\end{array}$ & Colorimetry & $\begin{array}{l}\text { Bromocresol green for total AL and CR } \\
\text { Jaffé picric acid for selective CR }\end{array}$ & {$[45]$} \\
\hline APBA and ESM & $\begin{array}{l}\text { Total hemoglobin and } \\
\text { glycated hemoglobin (HbA1c) }\end{array}$ & EIS & $\begin{array}{l}\text { Affinity sensor } \\
\text { Label-free } \\
\text { Paper-based SPCE }\end{array}$ & {$[46]$} \\
\hline APBA & HbA1c & EIS & $\begin{array}{l}\text { Affinity sensor } \\
\text { Label-free } \\
\text { Gold microelectrode array (IDA) chips }\end{array}$ & [47] \\
\hline CDP-choline & CRP & EIS & $\begin{array}{l}\text { Affinity sensor } \\
\text { Label-free } \\
\text { Phosphocholine-modified SPCE }\end{array}$ & {$[48]$} \\
\hline PMPC-SH & CRP & DPV & $\begin{array}{l}\text { Affinity sensor } \\
\text { Label-free } \\
\text { AuNPs modified SPCE }\end{array}$ & [49] \\
\hline- & Glucose & $\begin{array}{l}\text { Chronoampero- } \\
\text { metry }\end{array}$ & $\begin{array}{l}\text { Nonenzymatic sensor } \\
\text { CoPc/G/IL paper-based SPCE }\end{array}$ & {$[51]$} \\
\hline- & Glucose & $\begin{array}{l}\text { Chronoampero- } \\
\text { metry }\end{array}$ & $\begin{array}{l}\text { Nonenzymatic sensor } \\
\mathrm{Pt} / \mathrm{Au} / \mathrm{BDD} \text { electrode }\end{array}$ & {$[52]$} \\
\hline- & Creatinine & Amperometry & $\begin{array}{l}\text { Nonenzymatic sensor } \\
\mathrm{CuO} / \mathrm{IL} / \mathrm{ERGO} \text { modified paper-based SPCE }\end{array}$ & {$[53]$} \\
\hline- & Dopamine & SWV & $\begin{array}{l}\text { Nonenzymatic sensor } \\
\text { G/PANI/PS nanofiber-modified SPCE }\end{array}$ & {$[55]$} \\
\hline- & Dopamine & SWV & $\begin{array}{l}\text { Nonenzymatic sensor } \\
\text { SDS modified ePAD }\end{array}$ & {$[54]$} \\
\hline- & $\begin{array}{l}\text { Norepinephrine and } \\
\text { Serotonin }\end{array}$ & SWASV & $\begin{array}{l}\text { Nonenzymatic sensor } \\
\text { BDDPE }\end{array}$ & {$[56]$} \\
\hline- & $\begin{array}{l}\text { Norepinephrine, serotonin } \\
\text { and } p \text {-aminophenol }\end{array}$ & DPV & $\begin{array}{l}\text { Nonenzymatic sensor } \\
\text { Janus-ePAD } \\
\text { BDDPE }\end{array}$ & {$[57]$} \\
\hline
\end{tabular}

EIS: electrochemical impedance spectroscopy, DPV: differential pulse voltammetry, SWV: square wave voltammetry, SWASV: square wave anodic stripping voltammetry, SPCE: screen-printed carbon electrode, APBA: 3-aminophenyl boronic acid, ESM: boronate-modified eggshell membrane, CDP-choline: cytidine $5^{\prime}$-diphosphocholine sodium salt dihydrate, PMPC-SH: thiol-terminated poly(2-methacryloyloxyethyl phosphorylcholine), CoPc/G/IL: cobalt phthalocyanine-ionic liquid-graphene composite, Pt/Au/BDD electrode: Bimetallic Pt-Au nanocatalysts electrochemically deposited on boron-doped diamond electrode, CuO/IL/ERGO: copper oxide/ionic liquid/electrochemically reduced graphene oxide composite, G/PANI/PS: graphene/polyaniline/polystyrene, SDS modified ePAD: sodium dodecyl sulfate-modified electrochemical paper-based analytical device, BDDPE: boron doped-diamond paste electrode.

the total $\mathrm{Al}$ and $\mathrm{CR}$, while Jaffé picric acid was used for selective detection of $\mathrm{CR}$. The distinguished color change can be observed by the naked eye [45].

Affinity sensors are point-of-care devices based on either a biological recognition element or chemical recognition that are highly suitable for monitoring biomarkers [46]. For example, boronic acid and phosphocholine have been presented as chemical recognition sites for the detection of glycated hemoglobin [46, 47] and c-reactive protein [48, 49], respectively. Through the modification of these recognition molecules on the electrode surface, electrochemical detection was performed to examine the concentration of the target analyte.

Nonenzymatic electrochemical assays are another platform that is applied as a biosensor. Nonenzymatic biosensors are based on the catalytic reaction of the analyte of interest by a variety of materials on the electrochemical transducer [50]. The concentration of the analytes was determined by direct electrochemical detection. Nonenzymatic biosensors have been applied for the detection of many substances, such as glucose $[51,52]$, creatinine [53], dopamine [54,55], and neurotransmitters $[56,57]$. The merits of other applications are shown in Table 2. 


\section{CONCLUSION}

Various biosensor platforms have been developed and categorized based on their bioreceptors. Each type of biosensor presents fascinating properties. The development of biosensors mainly includes miniaturizing biosensors, automating operations, using novel biorecognition molecules, employing new material devices, and improving the analytical performance of biosensors towards target molecules. With a wide range of target molecules, many bioreceptors are used including enzymes, antigens/antibodies, nucleic acids, and synthetic receptors, and a variety of detection methods have been employed including electrochemical, colorimetric and spectroscopic detection. Thus, the development of biosensors plays an important role in many applications, such as those regarding the environment and food contaminants, especially in the diagnosis of many diseases. Future work should include the integration of technology that enables biosensors to be empowered in a wide range of applications with simple, user-friendly, inexpensive, less time analysis, low reagent and sample volumes.

\section{REFERENCES}

1. Mehrotra P (2016) Biosensors and their applications - A review. J Oral Biol Craniofac Res 6, 153-159.

2. Metkar SK, Girigoswami K (2019) Diagnostic biosensors in medicine - A review. Biocatal Agric Biotechnol 17, 271-283.

3. Bhalla N, Jolly P, Formisano N, Estrela P (2016) Introduction to biosensors. Essays Biochem 60, 1-8.

4. Asal M, Özen Ö, Şahinler M, Polatoğlu İ (2018) Recent developments in enzyme, DNA and immunobased biosensors. Sensors (Basel) 18, ID 1924.

5. Khansili N, Rattu G, Krishna PM (2018) Label-free optical biosensors for food and biological sensor applications. Sens Actuators B Chem 265, 35-49.

6. Hammond JL, Formisano N, Estrela P, Carrara S, Tkac J (2016) Electrochemical biosensors and nanobiosensors. Essays Biochem 60, 69-80.

7. Boobphahom S, Rattanawaleedirojn P, Boonyongmaneerat Y, Rengpipat S, Chailapakul O, Rodthongkum $\mathrm{N}$ (2019) $\mathrm{TiO}_{2}$ sol/graphene modified 3D porous $\mathrm{Ni}$ foam: A novel platform for enzymatic electrochemical biosensor. J Electroanal Chem 833, 133-142.

8. Neampet S, Ruecha N, Qin J, Wonsawat W, Chailapakul O, Rodthongkum N (2019) A nanocomposite prepared from platinum particles, polyaniline and a $\mathrm{Ti}_{3} \mathrm{C}_{2}$ MXene for amperometric sensing of hydrogen peroxide and lactate. Microchim Acta 186, ID 752.

9. Maluin FN, Sharifah M, Rattanarat P, Siangproh W, Chailapakul O, Issam AM, Manan SA (2016) Synthesis of PANI/hematite/PB hybrid nanocomposites and fabrication as screen printed paper based sensors for cholesterol detection. Anal Methods 8, 8049-8058.

10. Nantaphol S, Chailapakul O, Siangproh W (2015) Sensitive and selective electrochemical sensor using silver nanoparticles modified glassy carbon electrode for determination of cholesterol in bovine serum. Sens Actuators B Chem 207, 193-198.

11. Nantaphol S, Chailapakul O, Siangproh W (2015) A novel paper-based device coupled with a silver nanoparticle-modified boron-doped diamond electrode for cholesterol detection. Anal Chim Acta 891, 136-143.

12. Rattanarat $P$, Teengam P, Siangproh W, Ishimatsu R, Nakano K, Chailapakul O, Imato T (2015) An electrochemical compact disk-type microfluidics platform for use as an enzymatic biosensor. Electroanalysis 27, 703-712.

13. Ruecha $\mathrm{N}$, Rangkupan $\mathrm{R}$, Rodthongkum $\mathrm{N}$, Chailapakul O (2014) Novel paper-based cholesterol biosensor using graphene/polyvinylpyrrolidone/ polyaniline nanocomposite. Biosens Bioelectron 52, 13-19.

14. Dungchai W, Chailapakul O, Henry CS (2011) A low-cost, simple, and rapid fabrication method for paper-based microfluidics using wax screen-printing. Analyst 136, 77-82.

15. Ruecha N, Siangproh W, Chailapakul O (2011) A fast and highly sensitive detection of cholesterol using polymer microfluidic devices and amperometric system. Talanta 84, 1323-1328.

16. Dungchai W, Chailapakul O, Henry CS (2009) Electrochemical detection for paper-based microfluidics. Anal Chem 81, 5821-5826.

17. Apilux A, Siangproh W, Insin N, Chailapakul O, Prachayasittikul V (2017) Paper-based thioglycolic acid (TGA)-capped CdTe QD device for rapid screening of organophosphorus and carbamate insecticides. Anal Methods 9, 519-527.

18. Dungchai W, Chailapakul O, Henry CS (2010) Use of multiple colorimetric indicators for paper-based microfluidic devices. Anal Chim Acta 674, 227-233.

19. Yakoh A, Pinyorospathum C, Siangproh W, Chailapakul O (2015) Biomedical probes based on inorganic nanoparticles for electrochemical and optical spectroscopy applications. Sensors (Basel) 15, 21427-21477.

20. Apilux A, Ukita Y, Chikae M, Chailapakul O, Takamura Y (2013) Development of automated paperbased devices for sequential multistep sandwich enzyme-linked immunosorbent assays using inkjet printing. Lab Chip 13, 126-135.

21. Preechakasedkit P, Siangproh W, Khongchareonporn N, Ngamrojanavanich N, Chailapakul O (2018) Development of an automated wax-printed paper-based lateral flow device for alpha-fetoprotein enzymelinked immunosorbent assay. Biosens Bioelectron 102, 27-32. 
22. Ishii M, Preechakasedkit P, Yamada K, Chailapakul O, Suzuki K, Citterio D (2018) Wax-assisted one-step enzyme-linked immunosorbent assay on lateral flow test devices. Anal Sci 34, 51-56.

23. Preechakasedkit P, Pinwattana K, Dungchai W, Siangproh W, Chaicumpa W, Tongtawe P, Chailapakul O (2012) Development of a one-step immunochromatographic strip test using gold nanoparticles for the rapid detection of Salmonella typhi in human serum. Biosens Bioelectron 31, 562-566.

24. Preechakasedkit P, Ngamrojanavanich N, Khongchareonporn N, Chailapakul O (2019) Novel ractopamine-protein carrier conjugation and its application to the lateral flow strip test for ractopamine detection in animal feed. $J$ Zhejiang Univ Sci B 20, 193-204.

25. Apilux A, Rengpipat S, Suwanjang W, Chailapakul O (2020) Paper-based immunosensor with competitive assay for cortisol detection. J Pharm Biomed 178, ID 112925.

26. Preechakasedkit P, Osada K, Katayama Y, Ruecha N, Suzuki K, Chailapakul O, Citterio D (2018) Gold nanoparticle core-europium(iii) chelate fluorophoredoped silica shell hybrid nanocomposites for the lateral flow immunoassay of human thyroid stimulating hormone with a dual signal readout. Analyst 143, 564-570.

27. Apilux A, Rengpipat S, Suwanjang W, Chailapakul O (2018) Development of competitive lateral flow immunoassay coupled with silver enhancement for simple and sensitive salivary cortisol detection. EXCLI J 17, 1198-1209.

28. Charoenkitamorn K, Tue PT, Chikae M, Chailapakul O, Takamura Y (2018) Gold nanoparticle-labeled electrochemical immunoassay using open circuit potential for human chorionic gonadotropin detection. Electroanalysis 30, 1774-1780.

29. Dungchai W, Siangproh W, Chaicumpa W, Tongtawe P, Chailapakul O (2008) Salmonella typhi determination using voltammetric amplification of nanoparticles: A highly sensitive strategy for metalloimmunoassay based on a copper-enhanced gold label. Talanta 77, 727-732.

30. Jampasa S, Lae-ngee P, Patarakul K, Ngamrojanavanich N, Chailapakul O, Rodthongkum N (2019) Electrochemical immunosensor based on gold-labeled monoclonal anti-LipL32 for leptospirosis diagnosis. Biosens Bioelectron 142, ID 111539.

31. Charoenkitamorn K, Tue PT, Kawai K, Chailapakul O, Takamura Y (2018) Electrochemical immunoassay using open circuit potential detection labeled by platinum nanoparticles. Sensors (Basel) 18, ID 444.

32. Jampasa S, Siangproh W, Laocharoensuk R, Vilaivan T, Chailapakul O (2018) Electrochemical detection of c-reactive protein based on anthraquinone-labeled antibody using a screen-printed graphene electrode. Talanta 183, 311-319.
33. Pinwattana K, Wang J, Lin CT, Wu H, Du D, Lin Y, Chailapakul O (2010) CdSe/ZnS quantum dots based electrochemical immunoassay for the detection of phosphorylated bovine serum albumin. Biosens Bioelectron 26, 1109-1113.

34. Preechaworapun A, Ivandini TA, Suzuki A, Fujishima A, Chailapakul O, Einaga Y (2008) Development of amperometric immunosensor using boron-doped diamond with poly(o-aminobenzoic acid). Anal Chem 80, 2077-2083.

35. Yukird J, Wongtangprasert T, Rangkupan R, Chailapakul O, Pisitkun T, Rodthongkum N (2017) Labelfree immunosensor based on graphene/polyaniline nanocomposite for neutrophil gelatinase-associated lipocalin detection. Biosens Bioelectron 87, 249-255.

36. Ruecha N, Shin K, Chailapakul O, Rodthongkum $\mathrm{N}$ (2019) Label-free paper-based electrochemical impedance immunosensor for human interferon gamma detection. Sens Actuators B Chem 279, 298-304.

37. Boonkaew S, Chaiyo S, Jampasa S, Rengpipat S, Siangproh W, Chailapakul O (2019) An origami paper-based electrochemical immunoassay for the Creactive protein using a screen-printed carbon electrode modified with graphene and gold nanoparticles. Mikrochim Acta 186, ID 153.

38. Yakoh A, Chaiyo S, Siangproh W, Chailapakul O (2019) 3D Capillary-driven paper-based sequential microfluidic device for electrochemical sensing applications. ACS Sens 4, 1211-1221.

39. Jampasa S, Wonsawat W, Rodthongkum N, Siangproh W, Yanatatsaneejit P, Vilaivan T, Chailapakul O (2014) Electrochemical detection of human papillomavirus DNA type 16 using a pyrrolidinyl peptide nucleic acid probe immobilized on screen-printed carbon electrodes. Biosens Bioelectron 54, 428-434.

40. Jampasa S, Siangproh W, Laocharoensuk R, Yanatatsaneejit P, Vilaivan T, Chailapakul O (2018) A new DNA sensor design for the simultaneous detection of HPV type 16 and 18 DNA. Sens Actuators B Chem 265, 514-521.

41. Teengam P, Siangproh W, Tuantranont A, Henry CS, Vilaivan T, Chailapakul O (2017) Electrochemical paper-based peptide nucleic acid biosensor for detecting human papillomavirus. Anal Chim Acta 952, 32-40.

42. Teengam P, Siangproh W, Tuantranont A, Vilaivan T, Chailapakul O, Henry CS (2018) Electrochemical impedance-based DNA sensor using pyrrolidinyl peptide nucleic acids for tuberculosis detection. Anal Chim Acta 1044, 102-109.

43. Kongpeth J, Jampasa S, Chaumpluk P, Chailapakul O, Vilaivan T (2016) Immobilization-free electrochemical DNA detection with anthraquinone-labeled pyrrolidinyl peptide nucleic acid probe. Talanta 146, 318-325.

44. Teengam P, Siangproh W, Tuantranont A, Vilaivan T, 
Chailapakul O, Henry CS (2017) Multiplex paperbased colorimetric DNA sensor using pyrrolidinyl peptide nucleic acid-induced AgNPs aggregation for detecting MERS-CoV, MTB, and HPV oligonucleotides. Anal Chem 89, 5428-5435.

45. Chaiyo S, Kalcher K, Apilux A, Chailapakul O, Siangproh W (2018) A novel paper-based colorimetry device for the determination of the albumin to creatinine ratio. Analyst 143, 5453-5460.

46. Boonyasit Y, Chailapakul O, Laiwattanapaisal W (2016) A multiplexed three-dimensional paperbased electrochemical impedance device for simultaneous label-free affinity sensing of total and glycated haemoglobin: The potential of using a specific singlefrequency value for analysis. Anal Chim Acta 936, $1-11$.

47. Boonyasit Y, Laiwattanapaisal W, Chailapakul O, Emnéus J, Heiskanen AR (2016) Boronate-modified interdigitated electrode array for selective impedancebased sensing of glycated hemoglobin. Anal Chem 88, 9582-9589.

48. Boonyasit Y, Chailapakul O, Laiwattanapaisal W (2019) A folding affinity paper-based electrochemical impedance device for cardiovascular risk assessment. Biosens Bioelectron 130, 389-396.

49. Pinyorospathum C, Chaiyo S, Sae-ung P, Hoven VP, Damsongsang P, Siangproh W, Chailapakul O (2019) Disposable paper-based electrochemical sensor using thiol-terminated poly(2-methacryloyloxyethyl phosphorylcholine) for the label-free detection of Creactive protein. Microchim Acta 186, ID 472.

50. Si P, Huang Y, Wang T, Ma J (2013) Nanomaterials for electrochemical non-enzymatic glucose biosensors. RSC Adv 3, 3487-3502.

51. Chaiyo S, Mehmeti E, Siangproh W, Hoang TL,
Nguyen HP, Chailapakul O, Kalcher K (2018) Non-enzymatic electrochemical detection of glucose with a disposable paper-based sensor using a cobalt phthalocyanine-ionic liquid-graphene composite. Biosens Bioelectron 102, ID 11120.

52. Nantaphol S, Watanabe T, Nomura N, Siangproh W, Chailapakul O, Einaga Y (2017) Bimetallic Pt-Au nanocatalysts electrochemically deposited on borondoped diamond electrodes for nonenzymatic glucose detection. Biosens Bioelectron 98, 76-82.

53. Boobphahom S, Ruecha N, Rodthongkum N, Chailapakul O, Remcho VT (2019) A copper oxide-ionic liquid/reduced graphene oxide composite sensor enabled by digital dispensing: non-enzymatic paperbased microfluidic determination of creatinine in human blood serum. Anal Chim Acta 1083, 110-118.

54. Rattanarat P, Dungchai W, Siangproh W, Chailapakul O, Henry CS (2012) Sodium dodecyl sulfatemodified electrochemical paper-based analytical device for determination of dopamine levels in biological samples. Anal Chim Acta 744, 1-7.

55. Rodthongkum N, Ruecha N, Rangkupan R, Vachet RW, Chailapakul O (2013) Graphene-loaded nanofiber-modified electrodes for the ultrasensitive determination of dopamine. Anal Chim Acta 804, 84-91.

56. Nantaphol S, Channon RB, Kondo T, Siangproh W, Chailapakul O, Henry CS (2017) Boron doped diamond paste electrodes for microfluidic paper-based analytical devices. Anal Chem 89, 4100-4107.

57. Nantaphol S, Kava AA, Channon RB, Kondo T, Siangproh W, Chailapakul O, Henry CS (2019) Janus electrochemistry: Simultaneous electrochemical detection at multiple working conditions in a paper-based analytical device. Anal Chim Acta 1056, 88-95. 